\title{
AS REPERCUSSÕES DA PANDEMIA DO COVID-19 SOBRE OS MERCADOS DE TRABALHO: UMA ANÁLISE A PARTIR DE SANTA CRUZ DO SUL (RS).
}

\author{
HEINEN, V.'-; CADONÁ, M.A.2- \\ Palavras-chave: COVID-19, mercados de trabalho, Santa Cruz do Sul, precarização do trabalho.
}

\begin{abstract}
RESUMO
0 artigo analisa a dinâmica do mercado de trabalho de Santa Cruz do Sul, no Rio Grande do Sul, a partir da confirmação dos primeiros casos de Coronavírus no Brasil e das primeiras ações governamentais visando o enfrentamento da crise decorrente da Pandemia. Argumenta-se, no artigo, que para as pessoas que vivem do trabalho a experiência da pandemia intensificou a precarização do trabalho já vivenciada anteriormente. Nesse sentido, destaca-se que, no contexto das repercussões da Pandemia sobre os mercados de trabalho, se observou uma diminuição da capacidade de oferta de empregos formais e, ao mesmo tempo, as ações governamentais adotadas com o objetivo de "proteger os empregos" não impediram as demissões dos trabalhadores. 0 que se anuncia diante dessa realidade, num quadro de crise econômica e de políticas de "flexibilização do trabalho", são mercados de trabalho ainda mais desregulamentados, não somente com a diminuição das relações formais de empregabilidade, mas, também, com o aumento de trabalhadores precarizados.
\end{abstract}

\section{THE REPERCUSSIONS OF THE COVID-19 PANDEMIC ON THE LABOR MARKETS: AN ANALYSIS FROM THE LABOR MARKET IN SANTA CRUZ DO SUL (RS).}

Keyword: COVID-19, labor markets, Santa Cruz do Sul, job insecurity.

\begin{abstract}
The article analyzes the dynamics of the labor market in Santa Cruz do Sul, in Rio Grande do Sul, based on the confirmation of the first cases of Coronavirus in Brazil and the first government actions aimed at facing the crisis resulting from the Pandemic. It is argued, in the article, that for people who live from work the experience of the pandemic has intensified the precariousness of work already experienced previously. In this sense, it is highlighted that, in the context of the repercussions of the Pandemic on the labor markets, there was a decrease in the capacity to offer formal jobs and, at the same time, the government actions adopted with the objective of "protecting jobs" they did not prevent the dismissals of the workers. What is announced in the face of this reality, in a context of economic crisis and policies of "flexibilization of work", are even more deregulated labor markets, not only with the reduction of formal employability relations, but also with the increase of jobs. precarious workers.
\end{abstract}

\footnotetext{
${ }^{1}$ Acadêmica do oitavo semestre do Curso de Enfermagem na UNISC. É bolsista FAPERGS no Projeto "A dinâmica dos mercados de trabalho em cidades médias do Rio Grande do Sul: flexibilidade contratual, intermediação e proteção aos empregos". E-mail: vanessaheinen2011@hotmail.com.

2 Graduado em Filosofia, com Mestrado em Sociologia e Doutorado em Sociologia Política. É professor e pesquisador na UNISC, onde atua no Programa de Pós-Graduação em Desenvolvimento Regional (Mestrado e Doutorado) e no Departamento de Ciências, Humanidade e Educação. Coordenador do Projeto "A dinâmica dos mercados de trabalho em cidades médias do Rio Grande do Sul: flexibilidade contratual, intermediação e proteção aos empregos". E-mail: mcadona@unisc.br
} 


\section{INTRODUÇÃO}

Visando contribuir no acompanhamento das repercussões da Pandemia do Coronavírus sobre o trabalho e os mercados de trabalho no Brasil, o presente artigo analisa a dinâmica de admissões e de desligamentos no mercado formal do município de Santa Cruz do Sul, no Rio Grande do Sul, no período entre janeiro e maio de 2020. Um período, portanto, no qual os efeitos da Pandemia se intensificaram em todo o território brasileiro, levando os governos estaduais e municipais, na ausência de uma ação coordenada do governo federal, à adoção de medidas (variadas) de controle da proliferação da doença, de modo geral comprometidas com uma perspectiva de restrição às atividades socioeconômicas e de incentivo ao isolamento social.

Em especial os dados do "novo CAGED” (Cadastro Geral de Empregados e Desempregados), ${ }^{1}$ relacionados ao mercado formal de trabalho de Santa Cruz do Sul, são considerados como referência empírica para a análise. Importante considerar que o município de Santa Cruz do Sul tem uma população aproximada de cento e trinta mil habitantes, quatrocentos e dezenove habitantes (IBGE, 2019). Mais que um contingente populacional que coloca o município dentre os mais populosos do Rio Grande do Sul, Santa Cruz do Sul é uma importante referência na organização política e econômica da região onde está localizado, mas, também, na articulação dessa região com os circuitos estaduais, nacionais e, mesmo, internacionais de produção econômica e de poder político.

Nesse sentido, a cidade de Santa Cruz do Sul é uma importante "cidade média" do Rio Grande do Sul. Ou seja, uma cidade que, embora não esteja localizada na região metropolitana de Porto Alegre, apresenta "potencial de absorção" de investimentos, possui "algum tipo de economia de aglomeração", não "incorre em deseconomias de aglomeração, típicas das grandes metrópoles" (PEREIRA, LEMOS, 2003, p.127); e, principalmente, tem importância regional, na medida em que, como indicado, é uma referência para um determinado número de municípios em seu entorno (SPOSITO, 2007).

É a partir do mercado de trabalho formal de Santa Cruz do Sul, portanto, que o artigo analisa a dinâmica de admissões e de desligamentos entre os meses de janeiro e maio de 2020, considerando como essa dinâmica se manifestou entre homens e mulheres, entre os diferentes grupos de idade e de escolaridade, nos diferentes setores econômicos. Mais do que uma análise específica de uma realidade local, com o artigo pretende-se contribuir para ampliar a compreensão dos padrões existentes e das especificidades que decorrem das características locais e regionais de organização dos mercados de trabalho. Além disso, compromete-se com o debate sobre o processo de desestruturação dos mercados de trabalho no Brasil, aprofundado principalmente no contexto das crises econômicas e políticas vivenciadas no País a partir de 2014/2015, e sobre a necessária resistência das pessoas que vivem do trabalho a um processo de flagelo social que poderá se agravar em decorrência das respostas do capital aos "efeitos da Pandemia" sobre a economia do País.

\footnotetext{
${ }^{1}$ A partir de janeiro de 2020, a Secretaria Especial de Previdência e Trabalho, vinculada ao Ministério da Economia, substituiu o Sistema do Cadastro Geral de Empregados e Desempregados (CAGED) pelo "Sistema de Escrituração Digital das Obrigações Fiscais, Previdenciárias e Trabalhistas (eSocial) para "parte das empresas". Em função disso, os dados estatísticos do emprego formal no Brasil passaram a ser construídos tomando como base as informações captadas nos sistemas eSocial, Caged e Empregador Web. Para consultar esses dados ver: https://app.powerbi.com/view?r=eyJrljoiM2ZiNzk5YzUtODU50S00YjFmLTk1NjItNDY1M2IwMTJhOTgzliwidCI6ImNmODdjOTA4LTRhNjUtNGR IZS05MmM3LTEXZWE2MTVjNjMyZSISImMiOjR9
} 
Importante destacar, nesse sentido, que pesquisas realizadas sobre a dinâmica do mercado de trabalho de Santa Cruz do Sul, contemplando o período que se inicia durante a primeira década do século XX, indicam que as tendências observadas em nível nacional também se manifestaram no município. Assim, se ainda a partir dos anos 2000 houve um crescimento dos empregos formais, expresso esse crescimento numa maior oferta de empregos em relação ao número de trabalhadores demitidos, a partir de 2014 a situação apresentou mudanças, com uma diminuição das ofertas de empregos formais. Santa Cruz do Sul, portanto, a partir de 2014 acompanhou uma tendência nacional de maior precarização do trabalho, manifestação de situações de maior desemprego, do crescimento de empregos vulneráveis (meio-expediente, temporário, na informalidade), de comprometimento dos salários, de distanciamento em relação à proteção legal do trabalho (CADONÁ, BELARDINELLI, 2019; CADONÁ, 2019).

Há de se considerar, também, uma especificidade do mercado de trabalho de Santa Cruz do Sul, decorrente da importância que a produção industrial do tabaco tem no município. Conhecido por ser um município historicamente vinculado à produção de tabaco, no município estão localizadas as principais indústrias de tabaco do Brasil (Philip Morris, Souza Cruz, Japan Tobacco International, Universal Leaf Tobacos), responsáveis pelo processamento de grande parte da produção realizada no sul do país. Sob o ponto de vista do mercado de trabalho, da presença do setor fumageiro, além de colocar o município como um polo regional de empregos, resulta uma singularidade que está diretamente vinculada ao caráter sazonal da organização da produção industrial do tabaco: no município, um número significativo de trabalhadores atua em/disputa empregos temporários (na região, esses trabalhadores são chamados de "safristas"), de modo geral oferecidos nos primeiros semestres do ano (VOGT, 1997). Em decorrência, em Santa Cruz do Sul observa-se uma maior oferta de empregos nos primeiros semestres, invertendo-se essa situação nos segundos semestres, quando os trabalhadores safristas são desligados das indústrias fumageiras.

Por fim, cabe ainda neste texto introdutório destacar que a análise das repercussões do período pandêmico sobre os mercados de trabalho ganhou importância, não somente para o registro da dinâmica de empregos e desempregos a partir de então, mas, também e principalmente para uma melhor compreensão do alcance das políticas públicas que foram adotadas a partir de 2020 , direta ou indiretamente comprometidas com a amenização de situações de agravamento no desemprego e nas situações vulneráveis de empregabilidade. Foram essas políticas capazes de enfrentar uma já presente tendência de precarização do trabalho? Ou, numa outra direção, o contexto pandêmico, diante das decisões e ações tomadas, tanto pelas empresas quanto em decorrência das políticas públicas adotadas, agravou uma situação de precarização do trabalho já existe no país?

\section{MERCADO DE TTRABALHO DE SANTA CRUZ DO SUL NO CONTEXTO DA COVID-19}

As primeiras informações sobre o "novo coronavírus" chegaram ao Brasil no final de 2019, quando a doença ainda estava identificada como uma "epidemia" existente na China. No entanto, as primeiras ações relacionadas à pandemia do Covid-19 começaram em fevereiro de 2020, quando o governo nacional repatriou brasileiros que viviam em Wuhan, a cidade chinesa que naquele momento era o epicentro da infecção. Ainda naquele mês de fevereiro foi confirmado a primeira contaminação no País, progredindo esse número para 234 no dia 15 de março. Até então, entre polêmicas acerca da amplitude da doença, as medidas tomadas pelos 
governos eram tímidas e orientadas, de modo geral, por uma perspectiva de controle rápido, através do isolamento (quarentena) das pessoas infectadas, do maior cuidado com a entrada de pessoas no País, da testagem em internados em hospitais com quadro respiratório grave (OPAS/BRASIL, 2020).

As primeiras mortes e o crescimento do número de infectados no País (a primeira morte por coronavírus foi notificada pelo Ministério da Saúde no dia 17 de março), mesmo com forte relativização da importância da pandemia por parte de lideranças governamentais, em especial do Presidente da República, forçou os governos à adoção de medidas de controle da doença. Foi assim que a partir da segunda quinzena de março, os governos estaduais e municipais aumentaram as medidas de controle, através de estratégias que contemplaram a suspensão das aulas nas redes pública e privada, a restrição no funcionamento de estabelecimentos comerciais e de serviços, o maior controle sobre a circulação de pessoas em espaços públicos.

Contudo, além de descontínuas e envoltas em controvérsias, as políticas governamentais adotadas se mostraram incapazes de controlar o avanço da doença e suas consequências sobre a vida das pessoas. Tanto é assim que, desde meados de março até o início de agosto, mais de cem mil pessoas morreram e mais de três milhões pessoas foram infectadas pelo COVID-19, ${ }^{2}$ colocando o Brasil dentre os países onde a pandemia maiores efeitos teve e maior número de mortes provocou. Isso não significa que nada foi feito. Significa, no entanto, que a indisponibilidade dos governos, em especial do governo nacional, em assumir compromissos com políticas de estruturação das ações na área da saúde, de proteção às atividades econômicas e de proteção ao trabalho e à renda dos trabalhadores, resultou em custos altos sobre a vida da população, em especial das classes populares e de trabalhadores.

Em que pese as indisponibilidades políticas, ainda no começo de abril o Congresso Nacional aprovou um “auxílio emergencial" de $\mathrm{R} \$ 600,00$ (seiscentos reais), inicialmente por três meses e prorrogado pelo executivo nacional por mais dois meses no final de junho. 0 auxílio emergencial foi destinado a todas as pessoas com mais de 18 anos, desde que atendessem os seguintes requisitos: estivessem desempregadas ou exercendo atividades na condição de Microempreendedores Individuais (MEls), de contribuintes individuais da Previdência Social ou na informalidade; pertencessem a famílias cuja renda mensal per capita não fosse superior a meio salário mínimo ( $R$ \$ 522,00) ou cuja renda familiar total fosse de até três salários mínimos (R\$ 3.135,00) (CAIXA FEDERAL, 2020).

Observe-se que os seiscentos reais equivaliam a 57,4\% do valor do salário mínimo de 2020 (cujo valor era de $\mathrm{R} \$ \mathbf{1 . 0 4 5 , 0 0 )}$ e, nesse sentido, trata-se de um "auxílio" incapaz de atender necessidades básicas dos trabalhadores. E registre-se que, segundo dados da PNAD-Covid (Pesquisa Nacional por Amostra de Domicílios Covid), do IBGE, 38,7\% dos domicílios do País (ou 26,3 milhões de domicílios) tiveram acesso ao auxílio (IBGE, 2020). São dados que indicam uma situação de flagelo social, que pode se intensificar ainda mais, pois obriga milhões de brasileiros a se "virarem como podem", seja com o auxílio emergencial recebido, com a ajuda de familiares e de ações de solidariedade, mas, também, se sujeitando aos riscos da pandemia e realizando "trabalhos que aparecem".

Além dos riscos a que já estão sujeitos, a partir do segundo semestre de 2020 esses trabalhadores passaram a vivenciar um contexto econômico ainda mais agravado. Note-se, nesse sentido, que a mesma PNAD-

\footnotetext{
2 De modo preciso, no dia 09 de agosto o número de mortos pela COVID-19 no Brasil era de 101.049 pessoas, enquanto o número de infectados chegou aos 3.035.422 (dados do Ministério da Saúde) (BRASIL, 2020).
} 
Covid indicou que, em junho de 2020 , apenas $67,4 \%$ das empresas estavam funcionando "normalmente", $15 \%$ estavam temporariamente paradas pela pandemia e 17,6\% haviam encerrado definitivamente suas atividades (IBGE, 2020). De modo que, no segundo semestre de 2020, muitas pequenas e médias empresas que sobreviverem ficaram expostas a dívidas bancárias, quedas de receitas, impostos e alugueis em atraso. Um contexto desolador que se agravou ainda mais em decorrência da inibição dos gastos das famílias, que já repercutia tanto nas atividades de comércio quanto na produção industrial. Importante destacar que o IPEA (Instituto de Pesquisa Econômica Aplicada), ainda em julho de 2020 e partir de uma hipótese de "início de um processo de flexibilização gradual das restrições à mobilidade e ao funcionamento das atividades econômicas a partir de junho" (o que, efetivamente, não ocorreu, pois no final de julho os números de mortes e de infectados estava numa crescente), projetou uma queda do Produto Interno Bruto (PIB) do País de 10,5\% no segundo trimestre de 2020, com uma expectativa de que o ano terminasse com uma queda de $6 \%$ (uma expectativa construída com alto grau de incerteza, definida a partir da hipótese de um caminho "pós-pandemia" já no segundo semestre de 2020) (IPEA, 2020). O resultado final não confirmou a queda de 6\%, mas, no entanto, o PIB brasileiro teve uma queda de $4,1 \%$ naquele ano (IPEA, 2021).

As ações governamentais visando "proteger os empregos" também se voltaram ao mercado formal de trabalho. Contudo, não foram ações construídas a partir dos interesses dos trabalhadores, mas visando amenizar os efeitos da pandemia sobre as empresas e, portanto, sobre as perdas do capital. As medidas anunciadas, principalmente a partir de abril, compreenderam flexibilização da legislação trabalhista, redução de jornada de trabalho com corte de salário e suspensão de contrato, prorrogação do pagamento de tributos e contribuições, socorro financeiro a determinados setores (setor aéreo, de turismo e eventos, por exemplo), linhas de créditos para pequenas e médias empresas (NOGUEIRA, SILVA, CARVALHO, 2020). Dentre as medidas adotadas três delas merecem destaque: a Medida Provisória 936/2020 (MP 936/2020), a Medida Provisória 297 (MP 297/2020) e a Medida Provisória 944 (MPT 944/2020).

A MP 936/2020 permitiu a possibilidade da suspensão temporária de contratos de trabalho e a redução da jornada de trabalho com a redução proporcional do salário. Em relação à suspensão temporária dos contratos de trabalho (num prazo máximo de 120 dias), a medida garantiu, para as empresas com faturamento anual de até 4,8 milhões de reais, a suspensão sem pagamento do salário, responsabilizando-se o governo com $100 \%$ do seguro-desemprego que o trabalhador teria direito; para as empresas com faturamento superior aos 4,8 milhões, a suspensão com o pagamento de $30 \%$ do salário pela empresa, mais $70 \%$ do seguro-desemprego que o trabalhador teria direito garantidos pelo governo (NOGUEIRA, SILVA, CARVALHO, 2020, p. 9-10). Em relação à redução da jornada de trabalho com redução proporcional de salários, a medida garantiu a redução e jornadas/salários nas proporções de 25\%, 50\% e 75\%, também num prazo de 120 dias, com os salários sendo assumidos pelas empresas (NOGUEIRA, SILVA, CARVALHO, 2020, p. 9-10).

A MP 297/2020 apresentou dispositivos sobre "home office", férias individuais e coletivas, antecipação de feriados, adiamento do pagamento do FGTS, registro do COVID-19 como doença do trabalho. A referida medida provisória foi apresentada pelo executivo nacional para apreciação do Congresso Nacional no dia 22 de março, mas, embora tenha sido aprovada pela Câmara de Deputados, não foi votada no Senado até o dia 19 de julho, quando sua aprovação a transformaria em lei, perdendo sua validade. As medidas adotadas pelas empresas enquanto a MP estava em vigor, no entanto, não perderam sua validade. Dentre as permissões garantidas pela 
MP 297 estavam, durante o "período de calamidade": o teletrabalho, garantindo às empresas a adoção do teletrabalho; a antecipação das férias individuais; a concessão de férias coletivas; a antecipação de feriados; a criação de banco de horas; a suspensão de exigências administrativas em segurança e saúde no trabalho; a suspensão do recolhimento do Fundo de Garantia por Tempo de Serviço (FGTS) referente às competências de março, abril e maio, com vencimento em abril, maio e junho de 2020, respectivamente (MP 297/2020).

E a MP 944/2020 instituiu uma linha de crédito para as empresas, definindo como alvo as empresas com receita bruta anual superior aos $\mathrm{R} \$ 360$ mil e igual ou inferior aos $\mathrm{R} \$ 10$ milhões no exercício de 2019 . 0 empréstimo foi destinado exclusivamente ao pagamento de (no máximo) dois meses da folha de pagamento da empresa e limitou um teto de dois salários mínimos por empregado. Sobre os empréstimos incidiu uma taxa de juros de 3,75\% ao ano, com carência de seis meses e um prazo de amortização de até 36 meses. Em contrapartida, a MP comprometeu as empresas com a garantia do emprego, para todos os trabalhadores, por um período compreendido entre a data de contratação da linha de crédito e o sexagésimo dia após o recebimento da última parcela da linha de crédito (NOGUEIRA, SILVA, CARVALHO, 2020, p. 10).

As ações governamentais adotadas visando reduzir as repercussões no mercado formal de trabalho, no entanto, não impediram o aumento do desemprego no País. Os dados sobre os mercados de trabalho durante os primeiros meses de 2020 indicam que a partir de março, mas principalmente a partir de abril, se observou uma queda significativa no número de empregos e, em consequência, um aumento do já importante número de desempregados existentes no País. Nos mercados formais de trabalho, o aumento do desemprego fica evidente nos dados sobre admissões e desligamentos já a partir do mês de março, mas principalmente a partir do mês de abril (Quadro 01).

Quadro 01: Dinâmica de admissões e de desligamentos nos mercados formais do Brasil entre os meses de janeiro e maio de 2020.

\begin{tabular}{|l|c|c|c|}
\hline $\begin{array}{l}\text { Dinâmica } \\
\text { Meses }\end{array}$ & Admissões & Desligamentos & $\begin{array}{c}\text { Saldo (diferença entre } \\
\text { admissões e } \\
\text { desligamentos) }\end{array}$ \\
\hline Janeiro & 1.472 .059 & 1.356 .861 & 115.198 \\
Fevereiro & 1.566 .643 & 1.339 .291 & 227.352 \\
Março & 1.404 .847 & 1.657 .530 & -252.683 \\
Abril & 618.704 & 1.521 .545 & -902.841 \\
Maio & 703.921 & 1.035 .822 & -331.901 \\
\hline Total do período & 5.766 .174 & 6.911 .049 & -1.144 .875 \\
\hline
\end{tabular}

Dados: MINISTÉRIO DA ECONOMIA/Novo CAGED, 2020. Dados organizados pelos autores.

Observe-se no quadro que durante os dois primeiros meses do ano, o número de admissões foi superior ao número de desligamentos (115.198 admissões a mais em janeiro e 227.352 admissões a mais em fevereiro). Já em março essa situação se inverte, quando o número de desligamentos superou em 252.683 o número de admissões, aumentando significativamente essa diferença em abril, quando o número de desligamentos superou em 902.841 o número de admissões, e mantendo-se uma diferença significativa em maio, quando o número de desligamento superou em 331.901 o número de admissões. 
Essa dinâmica de admissões e de desligamentos no mercado formal é expressão, portanto, de um quadro de agravamento na situação de desemprego no País, já existente no período anterior à pandemia. Em maio de 2020, segundo dados do IBGE, a taxa de desemprego no País alcançou os 12,9\%, numa situação histórica em que, pela primeira vez, menos da metade da população em idade de trabalhar estava ocupada. Naquele mês de maio, 12,7 milhões de brasileiros estavam desempregados, tendo o País perdido em três meses 7,8 milhões postos de trabalho (desses, 5,8 milhões no mercado informal) (IBGE, 2020). Os postos de trabalho diminuíram entre os empregados com carteira assinada (diminuição de 2,5 milhões em três meses), entre os sem carteira assinada (diminuição de 2,4 milhões em três meses), entre os trabalhadores por conta própria (diminuição de 1,8 milhão em três meses), entre os trabalhadores domésticos (diminuição de 1,2 milhão em três meses) (IBGE, 2020).

No mercado formal de trabalho do município de Santa Cruz do Sul, a dinâmica de admissões e de desligamentos seguiu as tendências nacionais.

Antes da apresentação e análise desses dados, no entanto, cabe o registro dos procedimentos metodológicos adotados para a construção da análise. Como indicado ainda no texto de introdução, foram considerados dados secundários na análise, tendo como fonte principal os dados do NOVO CAGED, que registra informações mensais dos mercados formais (número de admissões, número de desligamentos, perfil socioeconômico de trabalhadores admitidos e desligados, escolaridade, idade e sexo de trabalhadores admitidos e desligados, estoque de empregos), organizadas por municípios. Foram, então, considerados esses dados, para o município de Santa Cruz do Sul e para os meses de janeiro a maio de 2020. A partir do registro e da sistematização dos dados, que consideram o universo de trabalhadores admitidos/desligados nos mercados formais de trabalho, foram construídos quadros, com o objetivo de perceber as tendências gerais presentes naquele primeiro período da Pandemia da COVID-19. 0 fato de considerar os dados relacionados aos primeiros meses de 2020 não implica, no entanto, que a perspectiva de análise se orientou pela intenção de elaborar uma fotografia, atentando apenas para as questões diretamente vinculadas àquele período. Pelo contrário, a análise se orientou pela possibilidade de compreender as repercussões da pandemia sobre empregos e desempregos, mas, também, das implicações de políticas governamentais que, já naquele momento foram adotadas visando diminuir possíveis efeitos negativos nos mercados de trabalho (desemprego, principalmente). Para além disso, no horizonte da análise está colocada uma discussão teórica sobre a situação dos trabalhadores no Brasil, em especial no contexto de crise econômica e política deflagrada no País a partir de 2014/2015, com o Impeachment de Dilma Rousseff e com o governo de Michel Temer.

A discussão teórica proposta está diretamente vinculada ao conceito de precarização, que expressa uma condição de inserção e de permanência dos trabalhadores nos mercados de trabalho caracterizada pela presença (permanente) do desemprego, pelo crescimento de empregos vulneráveis (seja no mercado informal, seja através de empregos temporários, de meio-expediente, intermitente etc.), pelo comprometimento da renda dos salários, pelo maior distanciamento em relação à proteção legal no trabalho, mesmo á fragilização das relações com instituições representativas dos interesses dos trabalhadores.

No Brasil, a precarização do trabalho, em especial no contexto de transformações que ocorrem no "mundo do trabalho" no País a partir das últimas décadas, pode ser identificada através de um "conjunto de indicadores" (DRUCK, 2011): 1. A precarização implicada e que decorre da "vulnerabilidade das formas de inserção" e das 
desigualdades sociais presentes nos mercados de trabalho do País (em 2009, 22\% dos ocupados com remuneração no Brasil recebiam menos do que um salário mínimo") (DRUCK, 2011, p. 48); 2. A precarização implicada e que decorre das diferentes formas de intensificação do trabalho e de dinâmicas de terceirização do processo produtivo, expressão de transformações tecnológicas e organizacionais nos processos de trabalho que tendem a impor aos trabalhadores "metas inalcançáveis", longas jornadas de trabalho, polivalência; e que se sustenta "na gestão pelo medo, na discriminação criada pela terceirização [...] e nas formas de abuso de poder" (DRUCK, 2011, p. 48); 3. A precarização implicada e que decorre das condições de insegurança e de saúde dos trabalhadores, dados os padrões de gestão que "desrespeitam o necessário treinamento, as informações sobre riscos, as medidas preventivas coletivas" (DRUCK, 2011, p. 49); 4. A precarização que implica a perda das identidades individual e coletiva, em condições nas quais a situação de desemprego e de "ameaça permanente da perda do emprego" se constituem "numa eficiente estratégia de dominação no âmbito do trabalho", decorrendo disso experiências de desenraizamento, de perda de vínculos, de corrosão da autoestima (num mundo que avisa aos indivíduos, a todo o momento, que "são inúteis para o mundo"), de destruição da solidariedade de classe (DRUCK, 2011, p. 50); 5. A precarização implicada e que decorre da fragilização da organização dos trabalhadores, dadas as crescentes dificuldades de organização sindical e de lutas em defesa de interesses coletivamente compartilhados pelos trabalhadores (DRUCK, 2011, p. 50); 6. Por fim, a precarização que está implicada e que decorre da "condenação e descarte do Direito do Trabalho", expressão dos ataques, questionamentos e relativização da importância das "formas de regulamentação do Estado, cujas leis trabalhistas e sociais têm sido violentamente condenadas pelos “princípios' liberais de defesa da flexibilização” (DRUCK, 2011, p. 52).

É a partir dessas discussões teóricas, portanto, que a análise sobre as repercussões da Pandemia da COVID19, nos primeiros meses de 2020 e sobre o mercado de trabalho de Santa Cruz do Sul, foi realizada.

Voltando, então, a análise já iniciada anteriormente, em Santa Cruz do Sul, durante os meses de janeiro, fevereiro e março observou-se um saldo positivo de admissões, mas a partir de abril o número de desligamento passou a superar o número de admissões, mantendo essa tendência no mês de maio. Observe-se, no entanto, que considerado o período entre janeiro e maio de 2020, o número de admissões superou em 2.159 o número de desligamentos (Quadro 02).

Quadro 02: Dinâmica de Admissões e de Desligamentos entre janeiro e maio de 2020 nas cidades médias consideradas.

\begin{tabular}{|c|c|c|}
\hline $\begin{array}{l}\text { Admissões/Desligamentos } \\
\text { Meses }\end{array}$ & A. & D. \\
\hline Janeiro & 2.538 & 1.889 \\
\hline Fevereiro & 3.793 & 1.527 \\
\hline Março & 2.457 & 1.936 \\
\hline Abril & 946 & 1.779 \\
\hline Maio & 1.212 & 1.456 \\
\hline Total & 10.946 & 8.787 \\
\hline
\end{tabular}

Fonte: MINISTÉRIO DA ECONOMIA/Novo CAGED, 2020. Legendas: A - Admissões; D - Desligamentos. Dados organizados pelos autores. 
Os resultados observados no período de análise estão diretamente vinculados à importância da indústria de tabaco no mercado de trabalho de Santa Cruz do Sul e ao modo de organização (sazonal) da produção industrial nesse setor. A produção agrícola chega na indústria fumageira no início do ano, quando então se inicia o processamento industrial do tabaco, requerendo a contratação de trabalhadores temporários (na região de Santa Cruz do Sul conhecidos como "safristas"). Esses empregos temporários duram, geralmente, seis/sete meses, quando então os trabalhadores são desligados das empresas. Como resultado, o mercado formal de trabalho de Santa Cruz do Sul tem uma dinâmica na qual nos primeiros semestres se observa um saldo positivo de empregos, invertendo-se esse saldo em favor das demissões nos segundos semestres. Mais do que um saldo em favor de demissões, trata-se de uma realidade na qual especialmente esses trabalhadores safristas vivenciam diferentes condições no mercado de trabalho: uns disputam empregos também temporários oferecidos nos segundos semestres; outros atuam no mercado informal nesses períodos, realizado especialmente atividades de serviços; outros vivenciam períodos intercalados de desemprego e ocupação temporária; outros, ainda, intercalam os períodos ocupados nas industrias com períodos em que ficam em suas casas, responsabilizandose pelas atividades familiares.

Além disso, nos primeiros meses de 2020 não se observou em Santa Cruz do Sul um agravamento da condição sanitária capaz de levar ao fechamento ou à restrição do funcionamento das empresas industriais. Nesse sentido, o processo produtivo de industrialização do tabaco não foi paralisado e as indústrias não alteram seus planos de produção.

No entanto, quando os dados do mercado formal de trabalho de Santa Cruz do Sul são analisados a partir dos diferentes setores econômicos, então se observa que os empregos nas atividades de comércio e de serviços foram atingidos. A capacidade de admissões nesses setores apresentou uma queda abrupta nos meses de abril e de maio. Meses esses nos quais as diferenças entre admissões e desligamentos aumentaram em favor dos desligamentos. Ao final do período analisado, assim, com exceção do setor industrial, os demais setores alcançaram saldos negativos, ou seja, com um maior número de desligamentos em relação ao número de admitidos. Destaque-se, por exemplo, que no setor do comércio, durante os meses de abril e maio foram contratados 208 trabalhadores, quando no mesmo período foram desligados 745 trabalhadores. Na mesma direção, no setor de serviços nesses dois meses foram contratados 376 trabalhadores, enquanto que o número de desligamentos alcançou 1.124 trabalhadores. Ao final do período analisado (entre janeiro e maio de 2020), enquanto o saldo positivo em favor das admissões na indústria foi de 3.903 , nos demais setores o saldo positivo foi em favor dos desligamentos: 618 desligamentos a mais no setor do comércio e 498 desligamentos a mais no setor de serviços (Quadro 03).

Quadro 03: Dinâmica de Admissões e de Desligamentos no mercado formal de Santa Cruz do Sul, por setores econômicos e no período entre janeiro e maio de 2020.

\begin{tabular}{|c|c|c|c|c|c|c|c|c|c|c|c|c|}
\hline \multirow{3}{*}{ Meses } & \multicolumn{4}{|c|}{ Comércio } & \multicolumn{4}{|c|}{ Indústria } & \multicolumn{4}{|c|}{ Serviços } \\
\hline & \multicolumn{2}{|c|}{$A$} & \multicolumn{2}{|c|}{$D$} & \multicolumn{2}{|c|}{$A$} & \multicolumn{2}{|c|}{$D$} & \multicolumn{2}{|c|}{$A$} & \multicolumn{2}{|c|}{$D$} \\
\hline & $n$. & $\%$ & $n$. & $\%$ & $n$. & $\%$ & $n$. & $\%$ & $n$. & $\%$ & $n$. & $\%$ \\
\hline Janeiro & 363 & 26,8 & 475 & 24,1 & 1.482 & 21,4 & 513 & 17,0 & 581 & 26,3 & 525 & 19,4 \\
\hline
\end{tabular}




\begin{tabular}{|l|c|c|c|c|c|c|c|c|c|c|c|c|}
\hline Fevereiro & 412 & 30,4 & 382 & 19,4 & 2.525 & 36,5 & 528 & 17,5 & 695 & 31,4 & 483 & 17,8 \\
Março & 372 & 27,5 & 371 & 18,8 & 1.425 & 20,6 & 841 & 27,9 & 560 & 25,3 & 578 & 21,3 \\
Abril & 76 & 5,6 & 478 & 24,2 & 675 & 9,8 & 582 & 19,3 & 164 & 7,4 & 628 & 23,2 \\
Maio & 132 & 9,7 & 267 & 13,5 & 812 & 11,7 & 552 & 18,3 & 212 & 9,6 & 496 & 18,3 \\
\hline Total & 1.355 & 100,0 & 1.973 & 100,0 & 6.919 & 100,0 & 3.016 & 100,0 & 2.212 & 100,0 & 2.710 & 100,0 \\
\hline
\end{tabular}

Fonte: MINISTÉRIO DA ECONOMIA/Novo CAGED, 2020. Legendas: A - Admissões; D - Desligamentos. Dados organizados pelos autores.

Os dados socializados pelo Novo-CAGED permitem analisar, também, a dinâmica de admissões e de desligamentos entre homens e mulheres e nos diferentes grupos de idade e de escolaridade.

Em relação à dinâmica de admissões entre homens e mulheres, como está indicado no quadro a seguir, os dados não permitem identificar diferenças significativas. É importante enfatizar que no mercado de trabalho brasileiro as mulheres são, historicamente, vítimas de diferentes formas de discriminação. São as mulheres que têm maiores dificuldades de encontrar uma ocupação, têm salários menores, estão mais afastadas de uma proteção legal no trabalho, ocupam atividades menos valorizadas na estrutura de empregos (DIEESE, 2000; 2012). Condições que não expressam a amplitude da discriminação sexual presente nos mercados de trabalho, mas que são indicativas dessa condição histórica de desigualdade. No entanto, sob o ponto de vista da dinâmica do mercado formal de Santa Cruz do Sul, durante os primeiros meses de 2020, embora tenham sido os homens que mais foram admitidos, também foram eles que mais foram desligados. Enfatize-se, portanto, que os dados analisados não autorizam conclusões precisas acerca das experiências de homens e mulheres nos mercados de trabalho analisados durante e a partir da pandemia; são dados que indicam que a situação desemprego atingiu tanto homens quanto mulheres (Quadro 04).

Quadro 04: Dinâmica de Admissões e de Desligamentos no mercado formal de Santa Cruz do Sul, por sexo, no período entre janeiro e maio de 2020.

\begin{tabular}{|l|c|c|c|c|c|c|c|c|}
\hline \multirow{2}{*}{ Sexo } & \multicolumn{4}{|c|}{ Homens } & \multicolumn{4}{c|}{ Mulheres } \\
\cline { 2 - 9 } Meses & \multicolumn{2}{|c|}{ Admissões } & \multicolumn{2}{c|}{ Desligamentos } & \multicolumn{2}{c|}{ Admissões } & \multicolumn{2}{c|}{ Desligamentos } \\
\cline { 2 - 9 } & $n$. & $\%$ & $n$. & $\%$ & $n$. & $\%$ & $n$. & $\%$ \\
\hline Janeiro & & & & & & & & \\
Fevereiro & 1.377 & 25,1 & 863 & 18,8 & 1.161 & 21,4 & 1.026 & 25,7 \\
Março & 1.816 & 33,0 & 810 & 17,7 & 1.977 & 36,4 & 717 & 17,9 \\
Abril & 1.266 & 23,0 & 1.151 & 25,1 & 1.191 & 21,9 & 785 & 19,6 \\
Maio & 450 & 8,2 & 958 & 20,9 & 496 & 9,1 & 821 & 20,5 \\
\hline Total & 628 & 11,4 & 805 & 17,5 & 584 & 10,8 & 651 & 16,3 \\
\hline
\end{tabular}

Fonte: MINISTÉRIO DA ECONOMIA/Novo CAGED, 2020. Legendas: A - Admissões; D - Desligamentos. Dados organizados pelos autores.

Na mesma direção, os dados sobre a dinâmica de admissões e de desligamentos entre os diferentes grupos de escolaridade não permitem análises conclusivas acerca de desigualdades afirmadas ou não durante e a partir da pandemia. Ainda que, quando são consideradas as admissões, é possível observar que os admitidos com ensino superior (incompleto ou completo) diminuem a participação no total dos admitidos nos meses de abril e de maio. Nesse sentido, pode-se até levantar a hipótese de que as empresas, no momento de agravamento 
da crise do COVID-19, controlaram mais as admissões com maiores salários; mas essa diminuição também pode estar vinculada a dinâmicas de racionalização das atividades administrativas, quer por que essas atividades diminuíram, quer por que passaram a ser realizadas no sistema "home office" (Quadro 05).

Quadro 05: Dinâmica de Admissões e de Desligamentos no mercado formal de Santa Cruz do Sul, por grupos de idade, no período entre janeiro e maio de 2020.

\begin{tabular}{|l|c|c|c|}
\hline \multicolumn{1}{|c|}{ Dinâmica } & Admissões & Desligamento & Saldo \\
Escolaridade & & 18 & 37 \\
\hline Analfabetos & 55 & 1.617 & 1.414 \\
Fundamental incompleto & 3.031 & 929 & 609 \\
Fundamental completo & 1.538 & 903 & 417 \\
Médio incompleto & 1.320 & 3.633 & 126 \\
Médio completo & 3.759 & 764 & -167 \\
Superior incompleto & 597 & 723 & -77 \\
Superior completo & 646 & 8.587 & 2.359 \\
\hline Total & 10.946 & & \\
\hline
\end{tabular}

Fonte: MINISTÉRIO DA ECONOMIA/Novo CAGED, 2020. Legendas: A - Admissões; D - Desligamentos. Dados organizados pelos autores.

O mesmo não se observa, no entanto, quando se considera a dinâmica de admissões e de desligamentos entre os diferentes grupos de idade. Os dados indicam que os trabalhadores com 50 anos ou mais, em virtude da maior frequência de pessoas situadas em grupos de risco nesse grupo de idades (idosos e portadores de doenças crônicas, como por exemplo diabetes e hipertensão), foram discriminados tanto no momento das admissões quanto no momento dos desligamentos. Pois, durante os primeiros três meses de $2020,18,1 \%$ dos admitidos e $10,4 \%$ dos desligados tinham 50 anos ou mais; durante os meses de abril e maio, no entanto, 8,8\% dos admitidos e $\mathbf{2 0 , 5 \%}$ dos desligados tinham 50 anos ou mais. Ou seja, as pessoas com mais idades passaram a ter maiores dificuldades para encontrar um trabalho a partir da pandemia e, ao mesmo tempo, ficaram mais sujeitas às demissões (Quadro 06).

Quadro 06: Dinâmica de Admissões e de Desligamentos no mercado formal de Santa Cruz do Sul, por grupos de idade, no período entre janeiro e maio de 2020.

\begin{tabular}{|c|c|c|c|c|c|c|c|c|c|c|c|c|}
\hline \multirow[t]{3}{*}{ Idades } & \multicolumn{4}{|c|}{$17-29$ anos } & \multicolumn{4}{|c|}{$30-49$ anos } & \multicolumn{4}{|c|}{50 anos ou mais } \\
\hline & \multicolumn{2}{|c|}{$A$} & \multicolumn{2}{|c|}{$D$} & \multicolumn{2}{|c|}{$A$} & \multicolumn{2}{|c|}{$D$} & \multicolumn{2}{|c|}{$A$} & \multicolumn{2}{|c|}{$D$} \\
\hline & $n$. & $\%$ & $n$. & $\%$ & $n$. & $\%$ & $n$. & $\%$ & $n$. & $\%$ & $n$. & $\%$ \\
\hline Janeiro & 1.010 & 21,9 & 851 & 22,1 & 1.116 & 24,5 & 813 & 23,1 & 412 & 23,1 & 225 & 18,4 \\
\hline Fevereiro & 1.447 & 31,4 & 749 & 19,5 & 1.553 & 34,1 & 632 & 17,9 & 793 & 44,5 & 146 & 12,0 \\
\hline Março & 1.154 & 25,0 & 1.022 & 26,6 & 914 & 20,1 & 729 & 20,7 & 389 & 21,8 & 185 & 15,2 \\
\hline Abril & 414 & 9,0 & 678 & 17,6 & 441 & 9,7 & 705 & 20,0 & 91 & 5,1 & 396 & 32,4 \\
\hline Maio & 586 & 12,7 & 544 & 14,2 & 528 & 11,6 & 644 & 18,3 & 98 & 5,5 & 268 & 22,0 \\
\hline Total & 4.611 & 100,0 & 3.844 & 100,0 & 4.552 & 100,0 & 3.523 & 100,0 & 1.783 & 100,0 & 1.220 & 100,0 \\
\hline
\end{tabular}

Fonte: MINISTÉRIO DA ECONOMIA/Novo CAGED, 2020. Legendas: A - Admissões; D - Desligamentos. Dados organizados pelos autores. 
Os dados apresentados, portanto, indicam que no período de pandemia, em virtude do agravamento da crise econômica, dos limites das políticas governamentais de proteção aos empregos e à renda dos trabalhadores, das estratégias adotadas pelas empresas, a precarização do trabalho já em curso no Brasil se intensificou. 0 desemprego não iniciou uma escalada de crescimento no contexto da Pandemia, pois em 2019, segundo dados do IBGE, 11,9\% da força-de-trabalho do País estava desempregada (IBGE, 2019). Um desemprego que não somente era mais alto em virtude do aumento do mercado informal durante o último período, que alcançou 41,1\% da força-de-trabalho no País, maior índice desde 2016 (IBGE, 2019). Um contexto que também comprometia a renda dos trabalhadores, que em 2019 viram o poder aquisitivo de seus salários diminuir em relação ao ano anterior: segundo dados da PNAD Contínua 2019, um em cada cinco brasileiros recebia metade do salário mínimo em 2019, quanto a renda média da metade dos trabalhadores ocupados era menor do que um salário mínimo (IBGE, 2019).

Não se pode relativizar, também, que nesse contexto de precarização o trabalho no País, a orientação política e ideológica que se tornou hegemônica no País com a eleição de Jair Bolsonaro, em 2018, favoreceu políticas de destruição dos escassos mecanismos de proteção ao trabalho que foram conquistados pelos trabalhadores a partir do processo de abertura política, na década de 1980. Nessa direção, em abril de 2020 , num momento em que a pandemia se agravava e, como indicado, o desemprego teve um salto significativo no País, a Câmara de Deputados aprovou, em sessão online, a Medida Provisória 905/2019, conhecida como "Medida Provisória da Carteira Amarela", de autoria do executivo nacional e comprometida com a desregulamentação e a flexibilização da legislação trabalhista (neologismo usado para encobrir a intenção de garantir liberdade para a destruição de direitos sociais e trabalhistas). Embora a Medida Provisória 905/2019 tenha sido revogada (pois o Senado não se posicionou em relação a ela durante o prazo legal), durante a sua vigência (de janeiro até 20 de abril de 2020) ela permitiu que as empresas contratassem trabalhadores com a possibilidade de pagamento de férias e décimo terceiro parcelados, com redução de 40\% para $20 \%$ sobre o FGTS (Fundo de Garantia por Tempo de Serviço) em caso de demissão sem justa causa, isenção da contribuição previdenciária, retirada dos sindicatos em discussão sobre participação de lucros e resultados, isenção de encargos sobre a folha de pagamento em salários limitados a 1,5 salário mínimo.

Para que as repercussões dessa Medida Provisória implicam sob o ponto de vista dos trabalhadores no País é importante que a mesma seja apresentada em seus principais pontos. Nesse sentido, destaque-se que dentre os principais pontos da Medida Provisória 205/2019 são: Limitação salarial: o valor do salário mínimo no ato do contrato era limitado a 1,5 salários mínimos; faixa de idade para contratação: o empregador poderia contratar empregados com idade entre 18 de 29 anos com os benefícios trabalhistas e previdenciários concedidos pela MP 905/2019; trabalho aos domingos: o trabalho aos domingos e feriados era autorizado, desde que previsto em contrato; contrato intermitente: o vínculo laboral por meio de contrato intermitente não era caracterizado como primeiro emprego para fins de contrato Verde e Amarelo, permitindo que o empregador recontratasse um empregado que já havia trabalhado como intermitente como contrato Verde e Amarelo; periculosidade: o adicional somente seria devido quando houvesse exposição permanente do trabalhador por, no mínimo, 50\% de sua jornada normal de trabalho; décimo terceiro salário: poderia ser paga antecipadamente de forma mensal, caso houvesse acordo ente as partes; férias mais 1/3 proporcional: poderiam ser pagas antecipadamente de forma mensal, caso houvesse acordo entre as partes; FGTS mensal: o recolhimento do FGTS 
era de $2 \%$ sobre a remuneração (e não de $8 \%$ como definia a legislação vigente); rescisão antecipada do contrato determinado: não se aplica a multa prevista pela CLT; multa do FGTS em caso de rescisão: a multa era de $20 \%$ se fosse paga antecipadamente de forma mensal, caso houvesse acordo entre as partes; participação nos lucros ou resultados: poderia ser objeto de negociação entre empresas e seus empregados, mediante comissão paritária escolhida pelas partes ou diretamente com o empregado; multa por infração trabalhista: as infrações eram divididas de acordo com a classificação (variável ou per capita), o porte econômico do infrator e natureza da infração (leve, grave ou gravíssima); encargos sociais: as empresas eram isentas de encargos sobre a folha de pagamento, desde que o salário pago ao empregado esteja limita a 1,5 salário mínimo).

Trata-se, portanto, de uma condição história favorável ao desenvolvimento do que Guy Standing (2017) adequadamente denomina "precariado", cuja existência enquanto trabalhador se distancia cada vez mais do horizonte de relações trabalhistas definidas a partir de uma agenda de "cidadania industrial". Um coletivo, em crescimento, de trabalhadores e de trabalhadoras que se caracterizam por diferentes formas de insegurança no trabalho: 1. Insegurança no mercado de trabalho - dadas as escassas oportunidades adequadas de renda e de salário; 2. Insegurança nos vínculos empregatícios - em virtude das possibilidades de dispensas arbitrárias, da desregulamentações sobre contratação e demissão, da maior possibilidade dos empregadores não serem penalizados pelo não cumprimento de regras trabalhistas; 3. Insegurança nos empregos - decorrente da dificuldade de manter "nichos no emprego", barreiras para a diluição de habilidade e, mesmo, profissões; 4. Insegurança nas condições de saúde no trabalho - em virtude da ausência ou falta de controle sobre práticas que colocam em risco os trabalhadores; 5 . Insegurança na "reprodução de habilidades" - decorrente das escassas ou individualização das oportunidades de adquirir habilidades através de treinamentos, bem como de fazer uso dos conhecimentos adquiridos; 6 . Insegurança na renda - como resultado da ausência ou da fragilidade de políticas capazes de garantir renda adequada e estável, protegida através de mecanismos de salário mínimo e de previdência social abrangente; 7. Insegurança de representação - dadas as ofensivas contra as formas de representação política dos trabalhadores e a crescente dificuldade do movimento sindical de fazer frente ao processo de precarização (STANDING, 2017, p. 28).

\section{CONCLUSÃO}

A análise apresentada teve como base os dados do novo Cadastro Geral de Emprego e Desemprego, referentes aos meses de janeiro a maio de 2020. E ficou circunscrita à dinâmica de admissão e demissão no município de Santa Cruz do Sul. 0 que se constatou indica uma consonância das realidades regionais com a dinâmica de admissão e desligamento em nível nacional. Os dados analisados comprovam que houve uma reversão, nos meses de abril e maio, da tendência observada nos meses de janeiro e de fevereiro, de incorporação no mercado formal de trabalho de um número maior de trabalhadores.

Esse resultado da pesquisa permite afirmar que a pandemia aprofundou a tendência estrutural de retração dos empregos. Essa constatação não ofusca a análise de que a dinâmica de admissão e demissão comportam algumas peculiaridades regionais. Elas estão vinculadas às singularidades de determinados ramos de atividades. No caso específico de Santa Cruz do Sul, essas singularidades remetem ao modo de organização da produção industrial no setor de beneficiamento do tabaco. A repercussão da supressão de postos de trabalho é menor 
nesse setor, tanto por que historicamente há maior contratação nos primeiros semestres dos anos, quanto por que se trata de um setor (setor industrial) cujas atividades poucas restrições tiveram em função da pandemia.

0 aprofundamento na retração do mercado formal de trabalho está em consonância com as propostas de desregulamentação da legislação social aprofundadas, na ultimada década, por setores empresariais e ancoradas nas decisões do Congresso Nacional e dos diferentes governos nacionais. Uma situação que permite reiterar que está em curso no Brasil um processo de aprofundamento da precarização das relações de trabalho.

0 contexto histórico que se impõe é de um capitalismo frente a uma sequência de crises que têm uma configuração de "ciclos" cada vez mais continuados e frequentes. As crises econômicas ocorrem em concordância com as crises de representatividade do Estado e das instituições da sociedade civil. Nesse sentido, a humanidade está envolta com um modelo proposto pelo capital de supressão e de precarização do trabalho, que acarreta uma concentração cada vez maior de riquezas. Uma situação dramática a qual, sob o ponto de vista da dignidade da maioria das pessoas, soma-se as crises dos fenômenos naturais e existenciais tais como as climáticas, as ecológicas, as de moradia, as de alimentação, as de preconceito racial, de gênero, as de exploração do trabalho de crianças e de adolescentes, a dos moradores originários etc.

Nesse sentido, é preciso que se avance no repensar a realidade, redefinindo as táticas e as estratégias a partir de uma análise crítica da natureza das instituições que foram forjadas no bojo da luta de formação da classe trabalhadora. Hoje, o desafio que se coloca paras as diferentes representações sindicais, por exemplo, é renovar-se no esforço de organizar mobilizações capazes de afirmar dinâmicas de resistência aos ataques cada vez mais frequentes aos direitos dos trabalhadores. Sabe-se que essa decisão, no contexto da mundialização do capital de "baratear o custo do trabalho", não é conjuntural, mas estrutural. No Brasil, a desregulamentação das relações de trabalho é feita em sintonia com a maioria dos deputados e senadores.

Há que se afirmar dinâmicas sociais e políticas que se distanciem de uma rígida divisão de funções na sociedade capitalista, legitimando o pressuposto segundo o qual as lutas pela vida digna devem ficar circunscritas às negociações entre os diferentes "agentes econômicos". Os sinais dos tempos presentes, enviados pela diversidade de mobilizações que ocorrem em diferentes partes do Planeta, indicam que esse paradigma vem sendo quebrado, na medida em que as ações sociais e coletivas não se dirigem e não são condicionadas somente pelas reivindicações circunscritas aos ditames da institucionalidade. Essas novas formas de lutar por reivindicações sociais são políticas e têm memória e historicidade sedimentadas, o que permite que sejam socializadas e a sua continuidade parta de um patamar de experiências, preservando-as e amplificando-as.

\section{REFERÊNCIAS}

ANTUNES, Ricardo. Desenhando a nova morfologia do trabalho: múltiplas formas de degradação do trabalho. Revista Crítica de Ciências Sociais, v.1, n.83 p.19-34, 2008.

BRASIL. Ministério da Saúde. Covid-19 no Brasil. In: https://susanalitico.saude.gov.br/extensions/covid19_html/covid-19_html.html. Consulta em: 02 ago. 2020.

. Presidência da República. Medida Provisória no 927, de 22 de março de 2020. Dispõe sobre as medidas trabalhistas para enfrentamento do estado de calamidade pública reconhecido pelo Decreto Legislativo no 6, de 20 de março de 2020, e da emergência de saúde pública de importância internacional decorrente do coronavírus (covid-19), e dá outras providências. Brasília: PR, 2020. 
Medida Provisória no 936, de 10 de abril de 2020. Institui o Programa Emergencial de Manutenção do Emprego e da Renda e dispõe sobre medidas trabalhistas complementares para enfrentamento do estado de calamidade pública reconhecido pelo Decreto Legislativo no 6, de 20 de março de 2020, e da emergência de saúde pública de importância internacional decorrente do coronavírus (covid-19), de que trata a Lei no 13.979, de 6 de fevereiro de 2020, e dá outras providências. Brasília: PR, 2020e.

CADONÁ, Marco André; BELARDINELLI, E. Perfil e dinâmica dos mercados de trabalho em cidades médias no Rio Grande do Sul: uma análise a partir de Caxias do Sul E Santa Cruz do Sul. Revista Brasileira de Gestão e Desenvolvimento Regional, v. 15, p. 168-180, 2019.

CADONÁ, Marco André. Experiências descontínuas de trabalho: uma análise a partir da dinâmica de admissões e de desligamentos nos mercados formais de cidades médias do Rio Grande do Sul. ÁGORA (UNISC. ONLINE), v. 21, p. 135-145, 2019.

CAIXA ECONÔMICA FEDERAL. Auxílio emergencial do governo federal. In: https://auxilio.caixa.gov.br/\#/inicio. Consulta em: 24 jul. 2020.

DRUCK, Graça. Trabalho, precarização e resistências: novos e velhos desafios. Cadernos CRH, Salvador, v. 24, n. spe 01, p. 37-57, 2011.

INSTITUTO BRASILEIRO DE GEOGRAFIA E ESTATÍSTICA (IBGE). Pesquisa Nacional por Amostragem de Domicílio - COVID 19 (PNAD-COVID-19). In: https://covid19.ibge.gov.br/pnad-covid/. Consulta em: 04 ago. 2020.

Pesquisa Nacional por Amostragem de Domicilios - 2019 (PNAD contínua 2019). In:

https://www.ibge.gov.br/estatisticas/sociais/rendimento-despesa-e-consumo/9173-pesquisa-nacional-poramostra-de-domicilios-continua-trimestral.html?edicao=26895\&t=destaques. Consulta em: 18 jul. 2020.

INSTITUTO DE PESQUISA ECONÔMICA APLICADA. Carta de Conjuntura - segundo trimestre 2020. In: https://www.ipea.gov.br/portal/index.php?option=com_content\&view=article\&id=35873\&ltemid=3. Consulta em: 04 de ago. 2020.

Carta de Conjuntura. Visão Geral da Conjuntura 2021. In:

https://www.ipea.gov.br/cartadeconjuntura/index.php/category/sumario-executivo/. Consulta em: 29 nov. 2021.

MINISTÉRIO DA ECONOMIA. Cadastro Geral de Empregados e Desempregados. Brasília: Ministério da Economia, 2020. In: http://bi.mte.gov.br/bgcaged/caged_perfil_municipio/index.php.

. Novo CAGED. Brasília: Ministério da Economia, 2020. In: http://pdet.mte.gov.br/novo-caged.

NOGUEIRA, Mauro Oddo; SILVA, Sandro Pereira; CARVALHO, Sandro Sacchet de. Socorro governamental às pequenas unidades produtivas frente à atual pandemia. Brasília: IPEA, 2020. (Nota Técnica, n. 63).

ORGANIZAÇÃO PAN-AMERICANA DE SAÚDE (OPAS). Informativo COVID-19 (doença causada pelo novo coronavírus). In:

https://www.paho.org/bra/index.php?option=com_content\&view=article\&id=6101:covid19\&Itemid=875. Consulta em: 03 ago. 2020.

SPOSITO, M. E. B. (org.). Cidades Médias: espaços em transição. São Paulo: Expressão Popular, 2007.

STANGIND, Guy. 0 precariado: a nova classe perigosa. Belo Horizonte: Autêntica, 2017. 